that "the Associution should look to themselves for the value of their publications, and those gentlemen who complain ought to reflect that the cure is in their own hauds;" and certainly the spirit, talent, and good feeling displayed at that meeting were an ample guarantee, that any Journal under its auspices must succeed, and live in health and strength, if gentlemen, (and there are 2000 Associates,) will but give themselves the trouble to feed $i t$. There are some very valuable examples to follow, and if my power equalled my inclination, the Journal should rarely be a week without a practical contribution. If the members of the Association would think of their Journal, and every one do his best to make it valuable, it would be the best medical periodical of the day.

In your number of July 23rd, there is a case of placenta prævia, related by Mr. Wilkinson, of Spalding. It must be presumed, that the head of the child was too high for the application of the forceps or lever; but when the operation of turning was effected, I should consider it questionable practice to wait an bour and a half before emptying the uterus and insuring its contraction, on which the safety of the patient depends. Mr. Wilkinson does not say that the scruple of ergot he exhibited produced any effect upon the uterus. Indeed, from long experience, I should say that the ergot of rye is not a medicine to depend upon. I have tried every preparation of it that has been brought out-bruised, powdered, boiled, infused, tincture, essence, oil, \&c.and they have all deceived me so repeatedly that $I$ have now discarded them all. Mr. Wilkinson's case is followed by another of the same nature, reported by $\mathrm{Mr}$. Tennent, of Brighton, in which that gentleman says, "I now administered half-drachm doses of the secale cornatum every half hour, till three doses had been given without in the smallest degree inducing perceptible uterine action, but with the effect of arresting the hamorrhage," that is to say, the ergot did not produce its specific effect, and yet the bæmorrhage ceased. I apprehend, if two table spoonfuls of cold water had been administered every half hour, the effect would have been exactly similar. One may apply a blister to a painful part, and from some mismanagement neither inflammation nor vesication follow, and yet the pain subside. I am not aware whether it is a common practice, in cases of uterine hæmorrhage, to administer a tumbler of cold water at a draught. I think I have seen much good from it.

$$
\begin{aligned}
& \text { I am, Sir, } \\
& \text { Very obediently, }
\end{aligned}
$$

Sheffield, August 9, 1845.

\section{W. FAVELL.}

\section{ON THE TREATMENT OF ANEURISM BY} COMPRESSION.

By W. R. Jolley, Esq., Surgeon to the Torbay Dispensary, \&c.

(Read at the Annual Meeting of the South Western District Branch of the Provincial Medical and Surgical Association.)

The treatment of aneurism by compression has very recently engaged the attention of the profession, and so successfully has this method been adopted, that $I$ doubt not but that every surgeon having the oppor- tunity, will avail himself of this simple mode of treatment, in preference to the ligature on the artery.

Three successful cases have been published; two by Mr. Liston, and one by Mr. Greatroux, surgeon of the Guards. I believe we are indebted to $\mathrm{Mr}$. Liston for this new era in surgery. I have now the pleasure of relating another interesting case, occurring in my own practice.

Thomas Wotton, aged 38, a green-grocer, residing in this parish, who had been suffering for the last three years from chronic disease of the bladder, which had much impaired his general health and strength, applied at the Torbay Dispensary, in July, 1844, to be admitted as a patient; he being confined to his bed, I visited him. He stated, that in April he used great exertion in walking from Teignmouth; when within a short distance of his abode, he was suddenly attacked with pain behind his right knee, and with difficulty reached home; on his arrival, he requested his wife to remove his stocking, when she found a swelling, of the size of a walnut, throbbing violently; he went to bed, but could not rest for the pulsation; the following morning he dressed himself, and attempted to walk, but failed.

July 15th. The tumour had much increased in size, and his nights were extremely restless. I prescribed hydrochlorate of morphia; middle diet; and a pint of porter daily for a week.

22nd. Several professional friends saw him, and examined the case, all of whom unhesitatingly were of opinion that it was popliteal aneurism, but, from the debilitated state of the system, not one for operation. Pergat.

23rd. It occurred to me that I would try the treatment adopted by Mr. Liston, and having procured a tournaquet, I placed it at the upper part of the thigh, maintaining pressure upon the vessel, and continued the morphia.

25th. The pressure of the instrument had caused considerable uneasiness, but no excoriation nor sloughing. Increased the hydrochlorate of morphia to threequarters of a grain at night.

27 th. Lessened the pressure of the instrument, as the patient complained of the great uneasiness and restlessness. Repeated the morphia.

30th. The patient appearing in better spirits, and strength improved. Increased the pressure of the instrument.

August 5 th. The tumour appears to have become more circumbscribed; he suffers less pain in his leg than formerly. Continued the morphia.

15th. The tumour is very hard, there is a slight pulsation, and the bruit is much less distinct than formerly.

25th. The leg was bandaged by a flannel-roller from the feet upwards, and a pad of lint placed over the aneurism.

Sept. 1st. No more severe pain; the tumour has considerably decreased, the murmur is still heard, but no pulsation is felt in it, or in the course of the artery between the aneurism and the seat of pressture:

10th. This day the presse-artère was removed, but the leg bandaged from the toes, and the compress lept grer the aneurism; there was slight cedema of the leg and thigh, but the feet were warm, and sensation was tolerably perfect. 
20th. Appeared to be perfectly free from any of the symptoms, and requested to be allowed to take exercise.

July 10, 1845. I have the pleasure of saying, that the condition of the patient affords me the opportunity of stating he is perfectly free from any symptoms of this once formidable disease.

\section{PUNCTURED WOUND OF THE ABDOMEN.}

TO THE EDITOR OF THE PROVINCIAL MEDICAL AND SrR, SURGICAL JOURNAL.

May I request the favour of the insertion of the following speedy recovery from a remarkable and dangerous injury, in the columns of your widely circulated Journal, should you consider it of sufficient interest.

$$
\begin{aligned}
& \text { I am, Sir, } \\
& \text { Yours obediently, } \\
& \text { SAMUEL SUMNER DYER, }
\end{aligned}
$$

King's College Hospital, Portugal Stroet, House Surgeon. Lincoln's Inn, August 11, 1845.

August 2nd. George Copley, aged four years, residing in Drury Lane, whilst playing with a lancet-pointed erasing knife, accidentally punctured his abdomen three inches above, and to the right of the umbilicus; he was immediately brought to the Hospital, with three inches of the omentum protruding from the small wound, from which there had been no bleedirg. Thè patient complained of but little pain; and as the returning of the protruded portion would have necessitated much handling,- and the probable consequence thereof-severe inflammation-I immediately cut it off to a level with the abdominal parietes; a small quantity of blood was uninterruptedly permitted to flow, before the application of a compress of lint, which was kept in its place with strapping and a bandage, and the patient wras put to bed.

3rd: He has'slept well all night; there is neither pain nor tenderness of abdomen; pulse tranquil; bowels have not been open.

4th. Still without any pain, or alteration of character of pulse; but the bowels being still confined, he took half an ounce of castor oil.

5th. No pain whatever; the bowels have been freely open; wound exposed, and has quite heuled: Ordered to resume his ordinary diet, for which broth and artowroot had been hitherto substituted.

\section{PROVINCIAL \\ Attedtaal \& Eurgical Iourmal. WEDNESDAY, AUGUST 20, 1845.}

Our legal friends have an old proverb, that " the man who conducts his own cause has a fool for his client.". We fear that the wisdom of him who is his own patient, does not stand in a less questionable light. A melancholy event which has recently oceurred to a respected member of our own proAdison forcibly sets forth the danger, not only of those who thus incautiously undertake the management of severe disease existing in their own persons, but also of the venturing without sufficient care on the administration of powerful medicinal agents, with the operation of which we are but imperfectly acquainted.

Dr. Male, of Birmingham, whose death bas been recently announced, fell a sacrifice, it appears, to these practices. He had been reading a work in which was recommended $a$ new and powerful agent, (aconite,) for the removal of deep-seated neuralgic pains, and having been suffering of late from an affection of this kind, which had resisted the ordinary means for its removal, he was induced to make trial upon his own person of the powers of the remedial agent recommended. Not sufficiently mindful of his age, Dr. Male took the tincture of aconite in doses, the accumulation of which produced an alarming depression of the nervous system, from which he was ultimately unable to rally, and thus fell a victim to that want of a due appreciation of the circumstances of his own case, so common, we may add, amongst medical men when treating themselves, combined with the incautious use of a powerful drug, with the operaw tion of which he was but imperfectly acquainted.

This unfortunate case should prove a warning to every medical practitioner, as well in the pursuit of his professional avocations; as in inducing him, when himself suffering under serious illness, to have recourse to the advice of some brother practitioner. But there is another class of practitioners to whom the warning may prove equally beneficial, while at the same time, it is infinitely more needed,-we mean such as are guilty of the insane practice of experimenting upon themselves or their fellow creatures, by employing powerful medicinal agents, with the properties and operation of which they are entirely unacquainted, and in cases of disease, of the nature and symptoms of which they are in like manner profoundly ignorant. We allude not here to those pests of society whose impudent and unprincipled traffic in human suffering and human life, is not simply permitted but actually protected by the government-the nostrummonger and the quack doctor; they are equally beyond shame on the one hand or conviction on the other. It is to those, who, influenced by the desire, we would fain hope, of administering relief to suffering, are ready to catch at each new remedy that appears, although unacquainted with its powers, and with the nature of the case in which they would employ it; whether such case be their own or that of another individual; to the domestic empiric, the amateur practitioner, and the practitioner of whatever denomination, who has not been by competent education and long and careful study. prepared to understand disease and its treatment. 